\title{
Evidence Based Information Prescription (IPs) in Developing Countries
}

\author{
Vahideh Zarea Gavgani \\ Department of Medical Library E Information Science, \\ Tabriz University of Medical Sciences, Tabriz,
}

Iran

\section{Introduction}

Information Prescription (IPs) is provision of specific evidence based health information to a specific individual/patient to help him/her understand, manage and control the ill health. Most of the time it is defined as prescription of right information to right person at right time (Kemper-Mettler, 2002a). Maybe this definition is the simplest way for describing a powerful complex process. To borderline the right person at right time and offer the right information at right time in practice is really huge work. Information prescription pledge active participation of patient in healthcare process. It promises that information intervention may boost the healthcare outcomes, reduce the medical errors and undertake the patients' right. But we need to clearly illustrate it in our practice. How information therapy and information prescription can boost health care, what is the differences between patient education and information prescription? How a piece of evidence based information can be given to a patient who should make decision about her $\backslash$ his health in an emergency condition? Is it really possible in practice? The philosophy of Ix and prescription of information to patient is perfect. It brings patient in the field and gives a colorful sense to patient centered healthcare. What is significant in this process is that every environment has its own norms, condition, beliefs, communication style and language, social and cultural features that influence in practicing Information therapy (Ix). IIt is essential to put information therapy into practice to find out an applicable model for a specific environment. Through this pilot model, appropriate protocols and guidelines can be developed to reach the best practice. Fulfillment of IPs relies on, at least, three components i.e. Information Technology (IT), Patients Preference and Physicians Interest. IT manifestations like Internet, social networking tools, mobile phone/computer facilities are widely available for patients and physicians equally, in developed countries. In such IT based environment patients are either seeking health information or have access to the net to communicate with their physicians, receive IPs, search for health information and share their story and information with their networks. In consequence, Information Prescriptions is now part of healthcare system of developed counties like US and UK.

\section{Our current status where $I x$ and IP to be practiced}

In Iran, as a sample of a developing country, almost $100 \%$ of patients demand for information prescription and information therapy service offered by hospital or the physician who offer 
healthcare services to them (Gavgani, 2011). Fortunately $97 \%$ of clinical specialists believe that patients have right to information therapy services and information prescription need to be given to patients as part of their healthcare service (Gavgani,2010-2011). Access to the internet is available for individuals and professionals through ADSL and Dial UP services. The speed is limited to 64MBPS, $128 \mathrm{mbps}$ higher for individual and professional. According to NetIndex the average download speed in Iran is $0.48 \mathrm{mbps}$ and higher in ranking the downloading speed of countries Iran ranks 167th among 168 countries (AsrIran,2011). Not all people afford high speed and unlimited internet access. The majority of ordinary internet users utilize 64 and 128 mbps speed internet access. All people do not have a computer to connect to the Internet, not all physicians uses computer with web in their office. Patients in Iran prefer to receive information therapy services in print format and most preferably in person from their health providers rather than Internet and library. However, mobile phone is also one of the most used devices by people for communication and transferring information therefore it also is a preferable device for delivering IPs to patients in Iran. Patients demand for information about diseases, treatments and medications (Gavgani, 2011). According to the above mentioned facts we had to adopt information therapy standards and guidelines to generate and develop an information therapy model applicable to our present situation with specific barriers that we face. We decided practice Information Therapy and Information Prescription for a limited subject area as a pilot project to find out the potentials, barriers, and driver forces in a model applicable for our social and cultural condition.

The main Objective of this project was provision of IPs for patients with cardiovascular problems, hospitalized in Shahid Madani Cardiology Hospital (Tabriz-Iran)from November 2011 to February 2011 ,during four months . It also aimed to detect the barriers and requirements for filling IPs in non-wired condition and reach to a sustainable and applicable model for fulfillment of IPs in developing and non-wired countries.

\section{Preparing data base for information therapy and information prescription}

Cardiovascular system and cardiac diseases includes a broad subject area especially it doubles when the other diseases interconnect with them. To identify the information services coverage we limited our service area to only coronary artery diseases (CAD). At first we extracted $\mathrm{MeSH}$ tree term map for $\mathrm{CAD}$ from $\mathrm{MeSH}$ data base (http://www.ncbi.nlm.nih.gov/mesh) [Figure1]. It enabled us to manage our information retrieval and storing model.

\begin{tabular}{|l|l|l|}
\hline CAD in relation with & CAD in Relation with & Cad in relation with Vascular \\
coronary disease & Arteriosclerosis & disease \\
\hline Coronary Artery Disease & Coronary Artery Disease & Coronary Artery Disease \\
BT:Cardiovascular Diseases & BT: Arteriosclerosis & [C14.907.585.250.260] \\
BT: Heart Diseases & BT: Arterial Occlusive Diseases & BT:Coronary Disease \\
BT: Myocardial Ischemia & BT:Vascular Diseases & BT:Myocardial Ischemia \\
BT: Coronary Disease & BT:Cardiovascular Diseases & BT: Vascular Diseases \\
& & BT: Cardiovascular Diseases \\
& & BT: Diseases Category \\
\hline
\end{tabular}

Fig. 1. Relation between CAD and other subjects according to $\mathrm{MeSH}$ 
According to the MeSH the broader terms / subjects for CAD can be recognized in coronary diseases, myocardial Ischemia, among heart disease. It also can be related to Arteriosclerosis, Arterial Occlusive Diseases and cardiovascular diseases. Therefore we prepared evidence based patient information for all the above mentioned three categories. Figure 2 presents tree numbers and entry terms in MeSH data base.

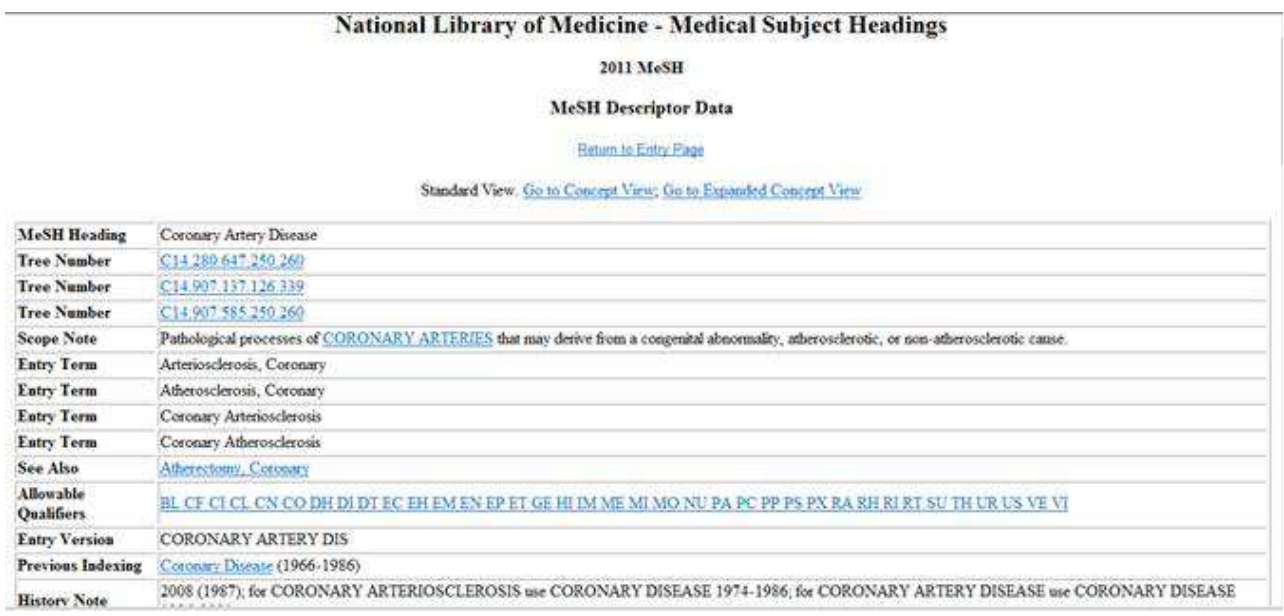

Fig. 2. Coronary Disease in MeSH tree

We extracted information from accurate resources including Cochrane library (www.cochrane.org), Medline Plus (www.nlm.nih.gov/medlineplus), MD Consult (www.mdconsult.com), RxList (www.rxlist.com/), Kaiser permanent (www.kaiserpermanente.org), Mayo Clinic (www.mayoclinic.com) and Pubmed clinical queries (http://www.ncbi.nlm.nih.gov/pubmed/clinical). According to Iranian nations cultural and religious background we also extracted description of a healthy heart from Holy Quran (http://www.parquran.com) and religious sources to use as standard for patient. We categorized information into three 1) Disease related health information: included information about diseases most of the time background information about Myocardial Infarction (MI), Myocardial Ischemia, Blood Pressure, Diabetics and in association with MI, Kidney Failure in relation with MI and so on. 2) Diagnostic information like Angiography. 3) Information for intervention which itself divided into two subcategories surgery, plus subcategories i.e. before and after operation, Angioplasty, CABG; and drug intervention such as Warfarin, Plavix, Aspirin, interaction and side effects of drugs. Our information prescriptions for after operational healthcare control and management of diseases was a little bit different information according to cultural and religious background of society. There are rich sources of Islamic rules in Quran (www.parsquran.com) and hadiths (saying) (http://www.tebyan.net/index.aspx?pid=65874; ) for sexual relationship, mental health and nutrition therefore unlimited relationships and alcohol were not cause and concern for these society. Instead concerns around performing prayer, sympathy and being deep imaginative in sorrowful incidents with religious root were negotiable. We prepared information on when to start exercise and sexual relationship, what kind of exercise and heavy 
works they can or can't do, how important is taking medicine on time and in a regular style for their recovery and disease control. We also included the side effects of eating much and bad eating style, time of and number of taking meal per day, some foods and activities according to Islamic rules and Quran. After extracting and collecting data we added value to information according to library science rules (Gavgani, 2009; 2011). Information translated into Persian , simplified and made readable with 6 and 7 grade. Then We used dicsern (www.dicsern.org.uk) questionnaire's criteria to build the structure of IPs and also Ix standards using Ix standards (Kemper-Mettler, 2002b). Finally, we stored information in simple database.

\section{Practice of Information Prescription (IPs) services}

We asked specialists whether they would like to practice information therapy and evidence based information prescription in a team work with information specialists. Two cardiologists accepted to work with us in information therapy and to prescribe information for their patients. Then we joined to the ward round as a team member, we noted down the problems while cardiologists were taking history, explaining the case to their assistants (residents). Physicians according to the hospitals traditional method used to give brief oral information to patients during the visit and history taking. But in this project despite of the traditional model cardiologists ordered personalized information for each case that is called information prescription when needed. It means that all information were not applicable for all patients in the ICU. For example a 36 year married man who had been operated with stent placement, and had drug addiction, smoking cigarette was prescribed information about Angioplasty, stent placement, drug, smoke and exercise. We prepared the information from the small database that we had made ready already, personalized it and submitted to the cardiologist, he approved information and one of the assistants offered information to the patient and explained it once orally to patient. Patient requested instruction for sexual relationship information. That is ordered again by assistant to our information team. We again extracted and personalized it and gave to specialist to approve or reject it.

The other case was a 60 year old woman with $90 \mathrm{~kg}$ weight who was accepted with heart attack and arrhythmia. She was also in inset of diabetics. She was prescribed information about pacemaker batteries, diet and lowering the weight, being alerted about airtime, sugar and LDL , HDL level, the risk of being diabetic and its relation with MI and heart attack. During taking history she said she can never go on diet because she is crazy of delicious foods with oil and sweets. We offered her extra information about Islamic instructions on eating style, quantity and time of taking food. Especially we stressed on the Islamic recommendation on "stop eating before you feel full".

A common model we used in our information prescription and information therapy service scenario is documented in a flowchart [Figure 3]. However it is significant to note that the process can be practiced with some differences according to the type of disease and patient's moment in care.

In some cases the only recommendation to patient is to repeat/to follow the previous instructions in such situation there would not be IP order therefore process will end with no need IP as shown in figure 3. 


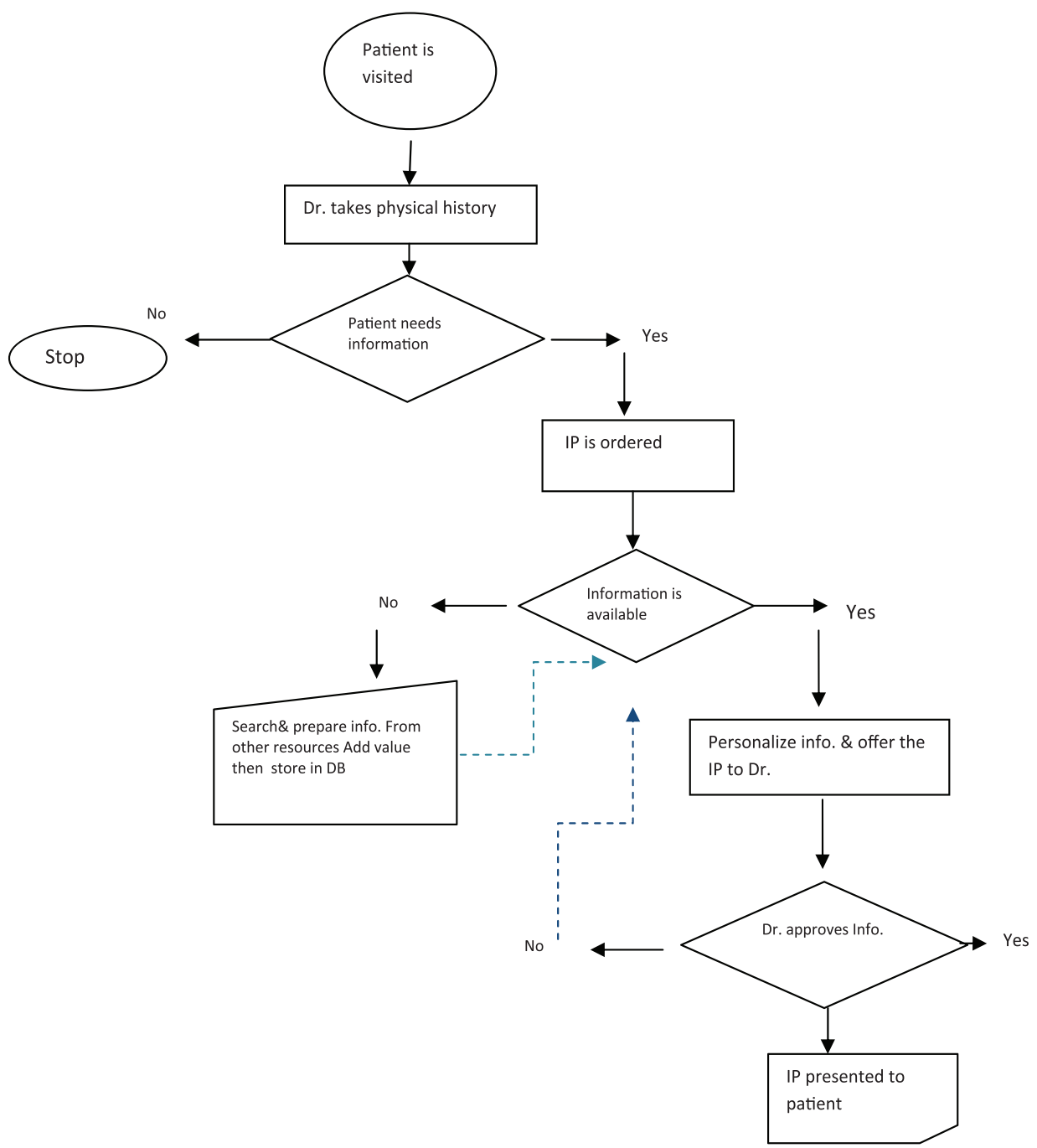

Fig. 3. The process of IP service in this project (flowchart)

\section{Result}

About 1500 patients with coronary Artery Disease (CAD) accepted in Shahid Madani Hospital during the months October to February 2010. The prescription were given only to those who candidate for state placement and were in professional relation with our two cardiologists. Total number of patients received IPs was 95. The average age of patients was 37.5. The youngest age was 34 and the oldest was 75. Major topics of IPs related to the Coronary Artery Disease (CAD) classified into four main categories including: diagnosis, treatment, surgery, medicine (Table 3). 


\begin{tabular}{|l|l|l|l|l|}
\hline \multicolumn{1}{|c|}{ Diagnosis } & \multicolumn{1}{|c|}{ Treatment } & \multicolumn{1}{c|}{ Surgery } & \multicolumn{1}{c|}{ Medicine } & \multicolumn{1}{c|}{ General } \\
\hline $\begin{array}{l}\text { Coronary } \\
\text { Angiography }\end{array}$ & $\begin{array}{l}\text { Therapeutic Lifestyle } \\
\text { Changes (TLC) } \\
\text {-Diet } \\
\text {---Dietary Approaches to } \\
\text { Stop Hypertension } \\
\text { (DASH) } \\
\text {-Exercise } \\
\text {-Weight control }\end{array}$ & Angioplasty & Effient & CAD \\
\hline $\begin{array}{l}\text { Cardiac } \\
\text { Catheterization }\end{array}$ & $\begin{array}{l}\text { Percutaneous Coronary } \\
\text { Intervention (PCI) }\end{array}$ & $\begin{array}{l}\text { Stent } \\
\text { placement }\end{array}$ & Aspirin & Other \\
\hline
\end{tabular}

Table 3. category of prescription given to the patients with CAD

The causes of CAD can be affected by different factors such as atherosclerosis, heart attack (angina), arrhythmia, sudden cardiac arrest (SCA), heart failure, diabetes, high blood pressure, high blood cholesterol. But in this study we excluded the causes and only included IPs related to the four above mentioned main categories, plus a category named "General" about CAD and other topics. The subcategory "other" includes information which was offered to patients by doctor's demand for specific cases or patients' request such as high blood pressure (HB), Sexual relations, Addiction, MI, religious recommendations and so on.

\begin{tabular}{|c|c|c|c|c|c|c|c|c|c|}
\hline 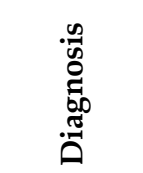 & $\begin{array}{c}F \\
(\%)\end{array}$ & $\begin{array}{l}\overrightarrow{0} \\
\text { क્口 } \\
\vdots \\
\omega\end{array}$ & $\begin{array}{c}F \\
(\%)\end{array}$ & 苞 & $\begin{array}{c}F \\
(\%)\end{array}$ & & $\begin{array}{c}F \\
(\%)\end{array}$ & تّٓ & $\begin{array}{c}F \\
(\%)\end{array}$ \\
\hline $\begin{array}{l}\text { Angiogr } \\
\text { aphy }\end{array}$ & \begin{tabular}{|l}
50 \\
$(82 \%)$
\end{tabular} & $\begin{array}{l}\text { Angiopl } \\
\text { asty }\end{array}$ & $\begin{array}{l}95 \\
(50 \%)\end{array}$ & Effient & \begin{tabular}{|l|}
94 \\
$(98 \%)$
\end{tabular} & TCI & \begin{tabular}{|l}
169 \\
$(97.7 \%)$
\end{tabular} & CAD & $\begin{array}{l}95 \\
(55.9 \%)\end{array}$ \\
\hline $\begin{array}{l}\text { Catheteri } \\
\text { zation }\end{array}$ & $\begin{array}{l}11 \\
(18 \%)\end{array}$ & Stent & $\begin{array}{l}95 \\
(50 \%)\end{array}$ & Aspirin & $\begin{array}{l}2 \\
(2 \%)\end{array}$ & PCI & \begin{tabular}{|l|}
4 \\
$(2.3 \%)$
\end{tabular} & other & $\begin{array}{l}75 \\
(41 \%)\end{array}$ \\
\hline Total & \begin{tabular}{|l}
61 \\
$(8.9 \%)$
\end{tabular} & & $\begin{array}{l}190 \\
(27.5 \\
\%)\end{array}$ & & \begin{tabular}{|l|}
96 \\
$(14 \%)$
\end{tabular} & & $\begin{array}{l}173 \\
(25 \%)\end{array}$ & & $\begin{array}{l}170 \\
(24.6 \%)\end{array}$ \\
\hline $\mathrm{N}=690$ & & & & & & & & & \\
\hline
\end{tabular}

${ }^{*}$ we separated the category of medicines from treatment and divided the category of treatment into PCI and TCI . Indeed, this study has taken place in heat surgery department not internal heart disease. Therefore, the two above mentioned medicines are only medications that usually are prescribed for patients after heart surgery. About other medications like infection control medicine we did not have IP order.

Table 4. Information offered for patients through their IP order 
CAD, Angioplasty and Stent are topics that were prescribed by doctor to all of the 95 patients, that undergone surgery (PCI: angioplasty and stent placement). In addition to the main information on the diseases and intervention totally Majority of topics offered to the patients in this study were about surgery $(27.5 \%)$, treatment ( $25 \%)$, General topics related to $\mathrm{CAD}$ and other information on ( $24.6 \%)$. The lowest percentage of topics prescribed for patients was about diagnosis techniques $(8.9 \%)$, and after that about medicines $(14 \%)$.

\section{Drivers and barriers}

Influencing factors were categorized into two groups: drivers and barriers. Some of the factors can act dual functionally in other word their presence helps the progress of process and their absence cut down and create difficulty for service. In such cases border line may be drown case vise.

\subsection{Drivers}

6.1.1 Patients' preference and demand for Information

6.1.2 Physician's interest and belief on providing IPs to patients

6.1.3 Number of Information specialist who are interested in Filling information prescriptions

6.1.4 Availability of more than $80 \%$ of demanded information

\subsection{Barriers}

6.2.1. Time: Time is the most critical component of information Therapy service . Ideally there should not be time gap between oral information that a physician gives to a patient and the information prescription which is Filled for patient. In the most preferred situation IP would better to be given to patient at the 10-15 minute visit time. IP also can be given along with the medications and Rx.

6.2.2. Integrated health information system (HIS): In an integrated HIS all the components of databases are coded, for example: ICD10 is used for coding diseases, NDC for drug, CPT for diagnostic tests and NLM for information. Coding enables the flow and circulation of information easy, fast and secure thought the system. In this project lack of such integrated system was crucial.

6.2.3 Confidence: confidence between health providers and patient is a two edge factor either driver or barrier for Ix and IPs.

6.2.4 Place: An identified place with at least 2 computer systems, internet connection, printer (color and or back and with) to receive, prepare and deliver prescriptions on time

6.2.5 ICT applications: Low speed internet connection is a critical barrier for successful Ix and IP services.

6.2.6 Mobile Technology: Mobile computer and mobile phone facilitate availability and accessibility of information. A mobile phone with printer can create shift in IPs service in ward round. Patient in developing countries use mobile phone more than web and they demand for mobile phone information delivery more than web or email delivery (Vishwa M., Gavgan V.Z, 2009). 
6.2.7 Database: Database of patient information is critical driver for Ix and IP services. Without having reliable information accessible, IP services will be time consuming process.

6.2.8 Patients's portal: Patient portal makes information available either from outside sources or from patient interactions.

6.2.9 Organizational support: Without organizational support, coordination and management it is impossible to practice Ix and IP in countries with centralized government and health system. We had limitation to take part in ward round or have access to patients' data because clinical librarianship concept does not practice formally in Iran.

6.2.10 Multimedia format: Availability of information in multimedia format is effective and efficient tool in understanding, learning and practicing prescribed information.

6.2.11 Literacy : Rural population are almost illiterate and it can be considered barrier if information supposed to be given in print format. Having information stored in different formats like audio and or audiovisual files can be used/offered in along with IP for better understanding.

6.2.12 Budget: Allocating money is also helpful in different aspects. It can be used in Critical situation that IPs team may face in providing and offering the service more effectively.

6.2.13 Confidentiality: Confidentiality is vital at least in patients-doctor relationship. Patient should be given guarantee that their health, mental and physical data is kept secure and will be used only for better health care. In some cases patients were worried about why should they are asking for specific questions and why should they are offered with specific information.

6.2.14 Communication style: In hospital setting clinicians give information about diseases and medications to patients orally. In conscious assent also it is usual to briefly explain the probable side effects, non effect and harms of intervention especially for surgery. But it is believed that the communication style, stress and pressure on words and procedures may effect in preference of patients (Nabhan A ,2011). Written information is documented and does not stress on type of intervention directly or indirectly.

\section{Conclusion}

The main Objective of this project was provision of IPs for patients with cardiovascular problems. The project successfully was conducted and the process of execution illustrated using flowchart. The other objective of study was finding drivers and barriers for IPs in Iran as a sample of developing country with lack of required facilities like electronic health record (EHR) and patient information services. The study found that despite of patients' preference and interest in receiving IPs, there are limitations for fulfillment of IPs in developing countries like Iran. Access to the Internet, electronic and integrated health records, patient information portals, availability of computer for individuals, health and computer literacy, are inconsistent throughout country. Therefore, it is essential to adopt both traditional paper based system and Information technology along with emerging IT based tools to ensure sustainability of IPs. The most significant barrier for Ix and IP service we faced in this project was cultural change and attitude of stakeholders including physicians, health providers and health consumers. Although physicians and nurses accept 
the theory of Ix and IP service and believe that patient has right to information and right information at right time to be made available for them. In practice they feel uncomfortable with it. Some of the health providers think that giving information to patients may create more and unnecessary jobs for health providers. Next to this issues the technical problems can be categorized in three including: 1) Time 2) Health information Technology and system 3) Training. Physicians time to accomplish IPs affected by many interconnected factors. One of the factors can be availability ICT and HIS. The last, HIS, is itself a big issue. Without HIS and patient information database/system it is very difficult for physicians to prescribe information even if they are appetite to empower their patients and get their feedbacks for shared decision making. Therefore; it can be said that at time, the biggest barrier to accomplish IPs in non wired and non-English language countries like Iran is lack of Patient Information system in vernacular languages like Persian. At least a patient information database is a significant factor to store, retrieve and personalize patient information in vernacular language at the moment of care. To overcome the time barrier on the side of physicians it is essential to consider the IPs as a essential component of physicians-patient communication in any visit.Physicians and residents need to be trained in prescription of information to their patients and other allied health providers like nurses also need to be trained to recognize the importance of IP s and its differences with the longstanding patient education in their profession. This study suggests that, to practice Ix and IPs successfully it is essential to create a framework in healthcare system in which every stakeholder and every particle of system including physician, nurse, informationist, social workers and patient look at health care promotion as a continual quality improvement goal. Patient care and information prescription need to be accepted as a best practice to empower patient. Protocols and guideline to be developed and made available for health providers and other stakeholders to enable them practiced Ix and IPs based of their own specific environment according to the facilities, barriers, cultural and ideological issues.

\section{References}

Kemper, D.W. \& Mettler, M. ( 2002a). Information Therapy prescribing the right information to the right person at the right time. Managed Care Quarterly, 10(4).

Gavgani V.Z. (2011). Information Therapy (Ix) and patients' preference. IGI Publishing Group. International Journal of Computational Models and Algorithms in Medicine (IJCMAM);2(2):42-50.

Gavgani V.Z. (2010-2011). An investigation to find out attitude of clinical faculty members about prescription of information patients therapy ; Unpublished research Project approved by Tabriz University of medical sciences-research deputy department. Code of ethics committee $5 / 4 / 8685$.

Asr Iran (2011).The latest situation of Internet Speed in Iran and Other countries . Asr Iran Newsletter20th othdibehesht, news code 165184. Retrieved from

< http:/ / www.asriran.com/fa/news/165184. >

A subject vise Hadith Databank (2011) Retrieve from

< http://www.aviny.com/hadis-mozooee/ejtemai/salamati.aspx>

Tebyan (2011). Nutriotin and health in Quran and hadith. Retrieved from < http:/ / www.tebyan.net/index.aspx?pid=65874> 
Nabhan A. (2011). Impact of reporting the number treated needlessly on perceived effectiveness and decision to adopt an intervention. 19th Cochrane Colloquium; Internation Conference on Patient Safety. 19-22 October 2011. Madrid . Retrieved from <http://colloquium.cochrane.org/abstracts/a2o1-impact-reporting-numbertreated-needlessly-perceived-effectiveness-and-decision-adopt $>$

Gavgani, V.Z. (2009). "Role of medical Librarians in information Therapy (Ix): study of problems and prospects in India and Iran". PhD.Thesis submitted to Osmania University, Hyderabad - India.

Gavgani V.Z. (2011). Role of librarians in information therapy (Ix): a comparative study of two developing countries. Aslib Proceedings: New Information Perspectives Vol. 63 (6): 603-617. DOI 10.1108/00012531111187252 Retrieved from

< http://www.emeraldinsight.com/journals.htm?issn=0001-253x\&volume=63\&iss ue $=6 \&$ articleid $=17004119 \&$ show $=$ abstrac $>$

Gavgani VZ (2011). 2nd conference of Information Therapy to put patient at first Prescription of Information for patient with Coronary Artery Disease. 9th October MumbaiIndia. Retrieved from < http:// patientpower.in/>

Kemper D.W. , Metler M.(2002b). Information Therapy:prescribed information as a reimbursable medical service, Boise, Healthwise.

Vishwa M, Gavgani V.Z. (2009) "Informing Clients Through ICT" . Issues in Informing Science and Information Technology, 6 :585-592. Retrieved from

<http:/ /iisit.org/Vol6/IISITv6p585-593Mohan622.pdf> 


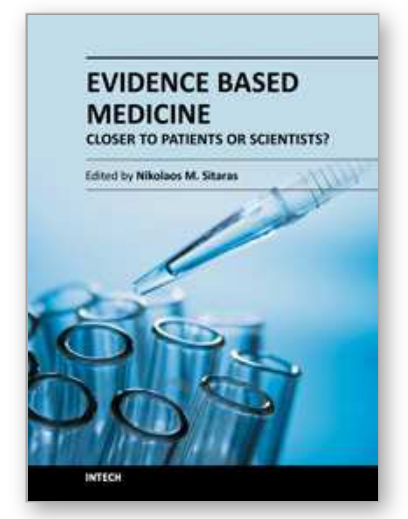

\author{
Evidence Based Medicine - Closer to Patients or Scientists? \\ Edited by Prof. Nikolaos Sitaras
}

ISBN 978-953-51-0504-6

Hard cover, 166 pages

Publisher InTech

Published online 11, April, 2012

Published in print edition April, 2012

Evidence-based medicine (EBM) was introduced to the best benefit of the patient. It has transformed the pathophysiological approach to the outcome approach of today's treatments. Disease-oriented to patientoriented medicine. And, for some, daily medical practice from patient oriented to case oriented medicine. Evidence has changed the paternalistic way of medical practice. And gave room to patients, who show a tendency towards partnership. Although EBM has introduced a different way of thinking in the day to day medical practice, there is plenty of space for implementation and improvement. This book is meant to provoke the thinker towards the unlimited borders of caring for the patient.

\title{
How to reference
}

In order to correctly reference this scholarly work, feel free to copy and paste the following:

Vahideh Zarea Gavgani (2012). Evidence Based Information Prescription (IPs) in Developing Countries, Evidence Based Medicine - Closer to Patients or Scientists?, Prof. Nikolaos Sitaras (Ed.), ISBN: 978-953-510504-6, InTech, Available from: http://www.intechopen.com/books/evidence-based-medicine-closer-topatients-or-scientists-/evidence-based-information-prescription-ips-in-developing-countries-

\section{INTECH}

open science | open minds

\section{InTech Europe}

University Campus STeP Ri

Slavka Krautzeka 83/A

51000 Rijeka, Croatia

Phone: +385 (51) 770447

Fax: +385 (51) 686166

www.intechopen.com

\section{InTech China}

Unit 405, Office Block, Hotel Equatorial Shanghai

No.65, Yan An Road (West), Shanghai, 200040, China

中国上海市延安西路65号上海国际贵都大饭店办公楼 405 单元

Phone: +86-21-62489820

Fax: $+86-21-62489821$ 
(C) 2012 The Author(s). Licensee IntechOpen. This is an open access article distributed under the terms of the Creative Commons Attribution 3.0 License, which permits unrestricted use, distribution, and reproduction in any medium, provided the original work is properly cited. 